\title{
Relationship among social support, treatment adherence and metabolic control of diabetes mellitus patients ${ }^{1}$
}

\author{
Lilian Cristiane Gomes-Villas Boas² \\ Milton Cesar Foss ${ }^{3}$ \\ Maria Cristina Foss de Freitas ${ }^{4}$ \\ Ana Emília Pace ${ }^{5}$
}

This cross-sectional and quantitative study aimed to analyze the relationship among social support, adherence to non-pharmacological (diet and physical exercise) and pharmacological treatments (insulin and/or oral anti-diabetic medication) and clinical and metabolic control of 162 type 2 diabetes mellitus patients. Data were collected through instruments validated for Brazil. Social support was directly correlated with treatment adherence. Adherence to nonpharmacological treatment was inversely correlated with body mass index, and medication adherence was inversely correlated with diastolic blood pressure. There were no associations between social support and clinical and metabolic control variables. Findings indicate that social support can be useful to achieve treatment adherence. Studies with other designs should be developed to broaden the analysis of relations between social support and other variables.

Descriptors: Social Support; Patient Compliance; Diabetes Mellitus; Nursing Care.

\footnotetext{
${ }^{1}$ Paper extracted from Master's Dissertation "Apoio social, adesão ao tratamento e controle metabólico de pessoas com diabetes mellitus" presented to Escola de Enfermagem de Ribeirão Preto, Universidade de São Paulo, WHO Collaborating Centre for Nursing Research Development, SP, Brazil.

2 RN, M.Sc. in Nursing, Adjunct Professor, Centro Universitário, Fundação Educacional Guaxupé, MG, Brazil. E-mail: liliancristianegomes@yahoo.com.br.

${ }^{3}$ Physician, Ph.D. in Medicine, Full Professor, Faculdade de Medicina de Ribeirão Preto, Universidade de São Paulo, SP, Brazil. E-mail: mcfoss@fmrp.usp.br.

${ }^{4}$ Physician, Ph.D. in Medicine, Professor, Faculdade de Medicina de Ribeirão Preto, Universidade de São Paulo, SP, Brazil. E-mail: crisfoss@fmrp.usp.br.

${ }^{5}$ RN, Ph.D. in Nursing, Associate Professor, Escola de Enfermagem de Ribeirão Preto, Universidade de São Paulo, WHO Collaborating Centre for Nursing Research Development, SP, Brazil. E-mail: aepace@eerp.usp.br.
}

Corresponding Author:

Ana Emília Pace

Universidade de São Paulo. Escola de Enfermagem de Ribeirão Preto

Departamento de Enfermagem Geral e Especializada

Av. dos Bandeirantes, 3900

Bairro: Monte Alegre

CEP: 14040-902, Ribeirão Preto, SP, Brasi

E-mail: aepace@eerp.usp.br 


\section{Relação entre apoio social, adesão aos tratamentos e controle metabólico de pessoas com diabetes mellitus}

O presente estudo objetivou analisar a relação entre apoio social, adesão aos tratamentos não medicamentoso (dieta e exercício físico) e medicamentoso (insulina e/ou antidiabéticos orais) e controle clínico-metabólico de 162 pessoas com diabetes mellitus tipo 2. Constituiu-se em um estudo seccional, de abordagem quantitativa. Os dados foram coletados por meio de instrumentos validados. O apoio social teve correlação direta com a adesão aos tratamentos. Observou-se correlação inversa entre adesão ao tratamento não medicamentoso e índice de massa corporal, bem como entre adesão medicamentosa e pressão arterial diastólica. Não houve associações entre apoio social e variáveis de controle clínico-metabólico. Conclui-se que o apoio social poderá ser útil para se obter a adesão aos tratamentos. Estudos com outros delineamentos devem ser desenvolvidos, a fim de se ampliar a análise das relações entre apoio social e outras variáveis.

Descritores: Apoio Social; Cooperação do Paciente; Diabetes Mellitus; Cuidados de Enfermagem.

\section{Relación entre apoyo social, adhesión al tratamiento y control metabólico de personas con diabetes mellitus}

El presente estudio objetivó analizar la relación entre apoyo social, adhesión a los tratamientos no medicamentoso (dieta y ejercicio físico) y medicamentoso(insulina y/o antidiabéticos orales) y control clínico-metabólico de 162 personas con diabetes mellitus tipo 2. Se trata de un estudio seccional, de abordaje cuantitativo. Los datos fueron recolectados por medio de instrumentos validados. El apoyo social tuvo correlación directa con la adhesión al tratamiento. Se observó correlación inversa entre adhesión al tratamiento no medicamentoso y índice de masa corporal, así como entre adhesión medicamentosa y presión arterial diastólica. No hubo asociaciones entre apoyo social y variables de control clínico-metabólico. Se concluye que el apoyo social podrá ser útil para obtener la adhesión a los tratamientos. Estudios con otros delineamientos deben ser desarrollados, a fin de ampliar el análisis de las relaciones entre apoyo social y otras variables.

Descriptores: Apoyo Social; Cooperación del Paciente; Diabetes Mellitus; Atención de Enfermería.

\section{Introduction}

Diabetes Mellitus (DM) stands out among nontransmissible chronic diseases because it is considered a public health problem due to its epidemic proportions. It constitutes a challenge to the health system and society because of the high financial and social costs to control and treat its complications ${ }^{(1)}$.

DM treatment aims to maintain metabolic control and basically comprises non-medication and medication therapy, the former of which is related to behavioral changes associated with a healthy diet and physical exercise $^{(2)}$. Clinical-metabolic control includes glucose control, through glycated hemoglobin and fasting plasma glucose measures, as well as blood pressure and plasma lipid (triglyceride, total cholesterol and fractions) control, as the latter two conditions generally coexist in DM patients, constituting risk factors for cardiovascular disease $^{(3)}$.

In this context, medication and non-medication treatment adherence represents a fundamental concept in care delivery to DM patients, and the understanding 
of barriers and facilitators for behavioral changes can support nursing interventions with a view to furthering or strengthening conditions that promote adherence.

This study highlights Social Support (SS) among the factors that might influence treatment adherence. SS is considered a complex and dynamic process that involves individuals and their social networks, working to satisfy their needs, provide and complement the resources they have and, thus, cope with new situations(4). The main sources can be family members and health professionals.

Studies suggest that SS is associated with adherence to medication and diet treatment. Others studies involving adults with DM revealed that people with a low SS perception presented significantly poorer glycemic control when exposed to highly stressful situations ${ }^{(5-6)}$.

Although treatment adherence and SS have been largely studied, little attention has been paid to the relation between treatment adherence and perceived social support, or to the need for this support among people with $\mathrm{DM}^{(7)}$. Assessing SS is important to help nurses to plan appropriate interventions that can enhance people's adaptation to their disease ${ }^{(8)}$ and, consequently, improve treatment adherence.

This study was developed in view of the need to know the perception of DM patients concerning SS and its relation to metabolic control and medication and nonmedication treatment adherence.

\section{Aim}

To analyze the relation between SS, non-medication treatment (diet and physical exercise) adherence, medication treatment adherence and clinical-metabolic control of type 2 Diabetes Mellitus patients under outpatient follow-up.

\section{Methods}

This sectional and quantitative study was carried out at a tertiary outpatient clinic in Ribeirao Preto, SP, Brazil between May and November 2008. The study population was selected through a weekly search of the medical profiles of people scheduled for appointments at the unit and who met the following inclusion criteria: minimum age of 40 years, medication treatment including insulin, oral anti-diabetic medication and/or associated medicines, absence of chronic complications in advanced stages, and ability to dialog. People older than 40 years were chosen because DM2 is most frequently diagnosed after this age.
Three instruments were used for data collection: Inventário da Rede de Suporte Social (IRSS), the translated version of The Social Support Network Inventory ${ }^{(9)}$, adapted and validated $(\alpha=0.95)$ for the Brazilian culture ${ }^{(8)}$, which serves to assess social network variables (source and type of contact) and perceived social support; Questionário das Atividades de Autocuidado com a Diabetes (QAAD), the translated version of the Diabetes Self-care Activities Questionnaire(11), adapted and validated $(\alpha=0.75)$ for the Brazilian culture ${ }^{(10)}$, which assesses adherence to diet and physical exercise recommendations; and the Medida de Adesão aos Tratamentos (MAT), the translated version of the Morisky Test ${ }^{(13)}$, adapted to and validated $\left(\alpha=0.74\right.$ ) for the Portuguese language ${ }^{(12)}$ and readapted to Brazilian Portuguese by Faria(14), which serves to assess medication treatment adherence.

The use of the instruments was previously authorized by the authors of the original versions as well as by the authors of the translated and adapted versions. Socio-demographic and clinical data, and information related to treatment and metabolic control (laboratory data) and life style were collected through a structured instrument that was tested in previous studies ${ }^{(15)}$.

The instruments were all read aloud, allowing the necessary time for each participant to fill them out. Data collection was carried out after the nature and objectives of the study had been clarified and participants had signed free and informed consent forms.

The collected data were stored in an Excel database, with double entry and validation. Afterwards, the database was exported to the Statistical Package for Social Science ${ }^{\circledR}$ (SPSS), version 11.5 for exploratory univariate and bivariate analyses with central trend measures (average and median) and variability (standard error) measures.

Numerical variables were submitted to the Kolmogorov-Smirnov test for distribution analysis and to the Levene test to verify the homogeneity of variances. The relationship between these variables was investigated through linear regression. The strength of the relationship was measured through Person's correlation coefficients and the degree of correlations was verified following the classification proposed by Zou, Tuncali and Silverman ${ }^{(16)}$ : weak $(r<0.3)$, moderate $(0.3<r<0.6)$, and strong $(r>0.6)$.

When categorical variables were evaluated in relation to a numerical variable, they were submitted to the previously mentioned tests of distribution and homogeneity. For the analysis between two independent 
samples, Student's $t$-test was applied; for more than two independent samples, data were submitted to variance analysis (ANOVA) followed by Tukey's test and the Kruskal-Wallis test, followed by Dunn's test when necessary, for parametric and non-parametric samples, respectively. The level of significance adopted in this study was 0.05 .

Approval for this study was obtained from the Institutional Review Board at the University of São Paulo at Ribeirão Preto Medical School Hospital das Clínicas on April 28 $8^{\text {th }}$ 2008, under protocol No 2049/2008, and participants received and signed the Informed Consent Term.

\section{Results}

During the study period, 1,004 people were attended at the outpatient unit and, after analysis of their medical records, 309 (30.8\%) met the inclusion criteria. Only 206 individuals could be contacted though. Of these, nine were excluded due to physical/cognitive limitations; 22 refused due to the following: concern with the medical appointment or transportation, did not see any benefit in participating in the study; 13 did not attend the meeting on the scheduled day and time. Therefore, the study sample comprised 162 people, which is equivalent to $16.1 \%$ of this study's baseline population.

The sample's socio-demographic profile is as follows: $94(58 \%)$ participants were women and 68 $(42 \%)$ were men. The average age was $59.4(\mathrm{SE}=8)$ years, 114 (70.4\%) were married, 67 (41.4\%) were pensioners, 129 (79.6\%) were from Ribeirão Preto, SP, Brazil and/or region, average education corresponded to $5.36(\mathrm{SE}=3.90)$ years and the monthly average family income was $\mathrm{R} \$ 1,325.65$ ( $S E=1,122.72$ ), which is equivalent to approximately 3.2 times the Brazilian monthly minimum wage at the time of study ${ }^{(17)}$.

The diagnosis time was, on average, 14.8 $(\mathrm{SE}=7.72)$ years; $88(54.3 \%)$ were obese and 58 $(35.8 \%)$ were overweight; $55.5 \%$ practiced regular or sporadic physical activity; $6.2 \%$ and $19.8 \%$ of the participants reported smoking and alcohol consumption, respectively. The most frequent complications/ comorbidities were dyslipidemia and hypertension; 104 (64.2\%) participants were under mixed insulin therapy and oral anti-diabetic medication; 143 (88.3\%) presented glycated hemoglobin higher than or equal to $7 \%$ (average=9.1\%; SE=1.82); average systolic blood pressure was $140 \mathrm{mmHg}(\mathrm{SE}=22.4)$ and diastolic
$78 \mathrm{mmHg}$ ( $\mathrm{SE}=11.84)$; average waist circumference for men was $106.4 \mathrm{~cm} \quad(S E=12.87)$ and for women $106 \mathrm{~cm}$ ( $\mathrm{SE}=13.87$ ); total cholesterol was $182 \mathrm{mg} / \mathrm{dl}$ $(\mathrm{SE}=47.7)$; HDL for men was $38 \mathrm{mg} / \mathrm{dl}(\mathrm{SE}=7.85)$ and for women, $45 \mathrm{mg} / \mathrm{dl}(\mathrm{SE}=9.16)$; triglycerides $215 \mathrm{mg} /$ dl (SE=237.3).

To check the reliability of the instruments used, in this study, Cronbach's alpha coefficient was calculated. The coefficients obtained for the IRSS, QAAD and MAT were, respectively, 0.94, 0.68 and 0.66. A psychometric property analysis review of instruments to assess subjective phenomena found that Cronbach's alpha coefficients higher than 0.50 are considered reasonable(18).

High levels of perceived SS were observed, with relatives as the main source, followed by health professionals. No statistically significant differences were found in mean SS with regard to gender, marital status and occupation. Weak but statistically significant correlations were observed though, between SS and age $(r=0.20 ; p=0.01)$, as well as between SS and education, the latter of which was an inverse correlation $(r=-0.23$; $p=0.03$ ). These data suggest that, the higher the age, the higher the perceived SS. On the opposite, the higher the education level, the lower the perceived $\mathrm{SS}^{(17)}$.

Non-medication treatment (diet and physical exercise) adherence was low in $69.1 \%$ of participants and an inverse and statistically significant correlation was found with education ( $r=-0.18 ; p=0.02)$, suggesting that, the higher this variable, the lower adherence. No statistically significant differences were observed in selfcare adherence measures regarding gender, marital status and occupation.

Medication treatment adherence was high for $95.7 \%$ of participants. No statistically significant correlations were found, though, between medication adherence and socio-demographic variables.

To study the relations among the main study variables, first, the relation between SS, medication and non-medication (diet and physical exercise) treatment adherence was analyzed. Direct but weak correlations were observed between SS and non-medication treatment adherence $(r=0.21 ; p=0.01)$, as well as between $\mathrm{SS}$ and medication treatment adherence $(r=0.18 ; p=0.02)$, suggesting that, the higher the perceived SS, the greater adherence to diet and physical exercise recommendations as well as to medication therapy.

The analysis of the relation among the (medication and non-medication) treatment adherence variables, 
with significance set at $\mathrm{p}<0.05$, revealed a direct and statistically significant but weak correlation among the scores $(r=0.22 ; p=0.00)$.
Finally, the relation among the SS variables, nonmedication treatment adherence, medication treatment adherence and clinical-metabolic control is shown in Table 1.

Table 1- Relation between social support, non-medication (diet and physical exercise) treatment adherence and medication adherence with clinical-metabolic control in the study sample. Ribeirão Preto, SP, Brazil, 2008

\begin{tabular}{|c|c|c|c|c|c|c|}
\hline \multirow{2}{*}{ Variable scores } & \multicolumn{2}{|c|}{ Social support } & \multicolumn{2}{|c|}{$\begin{array}{c}\text { Adherence to non-medication } \\
\text { treatment }\end{array}$} & \multicolumn{2}{|c|}{ Medication adherence } \\
\hline & $\begin{array}{l}\text { Statistical } \\
\text { coefficient* }^{*}\end{array}$ & $\mathrm{p}$ - value & $\begin{array}{l}\text { Statistical } \\
\text { coefficient* }^{*}\end{array}$ & p-value & $\begin{array}{l}\text { Statistical } \\
\text { coefficient }^{*}\end{array}$ & p-value \\
\hline Systolic arterial pressure $(\mathrm{mmHg})$ & 0.14 & 0.07 & 0.13 & 0.09 & -0.06 & 0.40 \\
\hline Diastolic arterial pressure $(\mathrm{mmHg})$ & 0.02 & 0.83 & 0.05 & 0.51 & -0.15 & $0.04^{\dagger}$ \\
\hline Body mass index $\left(\mathrm{kg} / \mathrm{m}^{2}\right)$ & -0.15 & 0.06 & -0.23 & $0.00^{\dagger}$ & -0.04 & 0.61 \\
\hline Waist circumference $(\mathrm{cm})$ & -0.15 & 0.06 & -0.15 & 0.05 & -0.06 & 0.46 \\
\hline Fasting plasma glucose (mg/dl) & 0.02 & 0.82 & -0.01 & 0.93 & 0.03 & 0.66 \\
\hline Glycated hemoglobin (\%) & 0.01 & 0.85 & -0.02 & 0.78 & -0.03 & 0.65 \\
\hline Total cholesterol (mg/dl) & 0.14 & 0.07 & -0.08 & 0.33 & -0.01 & 0.91 \\
\hline HDL cholesterol (mg/dl) & 0.01 & 0.93 & 0.00 & 1.00 & -0.04 & 0.59 \\
\hline LDL cholesterol (mg/dl) & 0.14 & 0.07 & -0.07 & 0.41 & -0.07 & 0.36 \\
\hline Triglycerides (mg/dl) & 0.04 & 0.60 & -0.06 & 0.44 & -0.03 & 0.73 \\
\hline
\end{tabular}

*The statistical coefficient corresponds to Pearson's or Spearman's correlation coefficient, according to the classification of the study sample.

+ Statistical significance $(p<0.05)$

No statistically significant associations are observed between clinical-metabolic control and SS. With $p$ set at $<0.05$, an inverse and statistically significant but weak correlation was observed between non-medication treatment adherence and BMI, as well as between medication adherence and diastolic blood pressure (Table 1).

\section{Discussion}

The relation between SS and socio-demographic characteristics in the study sample was explored in an earlier study(17). In that study, a direct correlation was highlighted between SS and age, as well as an inverse correlation with education.

SS was directly correlated with medication and nonmedication treatment adherence, in line with literature findings(7,19-20). The influence of family members and significant others may reinforce the health orientations DM patients receive, which could lead to higher adherence to diet and physical exercise recommendations as well as to medication treatment. On the other hand, this influence might conflict with health recommendations and hinder adherence ${ }^{(21)}$.

In the study group, a direct correlation was observed between the two adherence types under analysis. As opposed to literature, this finding suggests a close relation among different adherence aspects( ${ }^{(22)}$.
This might be relevant for interventions to improve adherence, that is, if one behavior tends to predict another, the same intervention might be an efficient means to increase adherence in more than one aspect of the treatment.

The correlation between SS and clinical-metabolic control was not statistically significant. Similar results were observed in two other studies. The first aimed to analyze the relation between SS, medication and non-medication treatment adherence and metabolic control in North American adult DM patients(23), while the second focused on the effects of SS on the health, well-being and metabolic control of adult African DM patients ${ }^{(24)}$. The later study, however, showed that SS is an important determinant of DM patients' health and well-beings. It also benefits at least one aspect of disease management, which is blood pressure control.

This study's findings reveal a weak inverse correlation between adherence to non-medication treatment (diet and physical exercise) and the Body Mass Index (BMI). This data reinforces the importance of diet and physical exercise recommendations in BMI control. A study that investigated the relation between medication and non-medication treatment adherence and DM control in Jamaican adults found similar results $^{(25)}$.

Regarding medication adherence, a weak inverse correlation was observed between this variable and 
mean diastolic blood pressure levels. In a study aimed at determining medication adherence among North American adult DM patients and its relation with the number of drugs prescribed and metabolic control, lower diastolic blood pressure levels were also identified among participants with higher medication adherence, although another instrument was used to assess adherence(26).

For glucose control, assessed through glycated hemoglobin levels, no statistically significant correlations with SS were observed, similar to another study cited ${ }^{(23)}$. No correlations were observed either between glycemic control and adherence variables, as opposed to authors who studied the relation between adherence and metabolic control among Finish adult DM patients ${ }^{(7)}$. It is highlighted that the latter study used another instrument for SS analysis.

In summary, the analysis of the relations between SS, medication and non-medication treatment adherence and clinical/metabolic control revealed that this study's findings are similar to those of studies carried out with DM patients, focusing on the relation between SS and adherence variables ${ }^{(7,19-20)}$, but diverge from the results of these same studies in terms of the relationship between SS and glycemic control, as well as between adherence variables and glycemic control.

On the other hand, the lack of association between adherence variables and glycemic control was also observed in another study ${ }^{(26)}$, without ignoring its clinical importance for care delivery to DM patients though.

Although a high glycated hemoglobin level suggests "something is wrong", this result does not specifically indicate what is wrong with the medical recommendations, or with the patient's disease management, which suggests that other factors, like the socioeconomic, cultural and occupation, exert influence(22).

Metabolic control is a complex set of interactions, in which adherence is only one of the many related factors, and that is why its use as an adherence measure is of limited value(22).

\section{Conclusion}

Even though no statistically significant correlation was observed between SS and clinical/metabolic control, one can infer on the clinical importance of SS when its effect on behavioral changes for self-care is observed. This effect has been shown in the studied literature, which emphasizes the influence of SS on DM management and the maintenance of preventive or health protection behaviors.
The literature has presented controversial results concerning the relation between adherence and metabolic control, sometimes in line with, sometimes differing from the present study. It is believed that many other variables can influence metabolic control. Psychological factors like health beliefs and sociocultural inequities might exert an interaction effect and, directly or indirectly, influence DM control.

It should also be taken into account that adherence to the therapeutic regimen, as opposed to metabolic control, is seen as a human behavior which, as such, is subject to direct influences from the social environment individuals live in.

In conclusion, SS can be a valuable resource, capable of helping people to adapt better to the demands the disease imposes, and is an important tool for health professionals, especially nurses. Knowing the process and structure of SS permits a better understanding of the way people's social relationships occur, and how these relationships can facilitate or enhance behaviors that promote and/or protect health.

It is also highlighted that most studies aim to analyze the relations between psychosocial variables and adherence, or between psychosocial variables and metabolic control. Few studies, however, have simultaneously investigated the relations between these three sets of variables, which justifies further studies of this kind.

Some limitations need to be taken into account. The first refers to the type of study. As it assesses SS and treatment adherence in a certain time period only, this does not permit capturing possible influences of vital events on perceived support and treatment adherence behaviors. Knowledge on these influences could provide important information for nursing intervention planning, as it permits understanding people in their daily life context.

Literature suggests that the evaluation of SS through indirect methods (self-reports) does not reveal the extent to which perceived support reflects actual support behaviors, as individual personality traits can also influence perceptions. The same applies to treatment adherence, since evaluating these variables through these same methods depends on the respondents' memory capacities and on their personal willingness to actually reveal their behaviors concerning therapeutic recommendations. In addition, researchers need to be skilled in collecting information in a neither inductive nor coercive manner.

Therefore, further research in the field should be encouraged, with different designs and larger population 
samples, in order to broaden the analyses of the relations between SS and other variables, and also to study the influences of nursing interventions in the recognition, change or reinforcement of social support to improve patients' health-disease conditions.

\section{References}

1. American Diabetes Association. Economic Costs of Diabetes in the U.S. in 2007. Diabetes Care. 2008;31(3):596-615.

2. Lerman I. Adherence to treatment: a key for advoiding long-term complications of diabetes. Arch Med Res. 2005 May-Jun; 36(3):300-6.

3. American Diabetes Association. Standards of Medical Care in Diabetes. Diabetes Care. 2011 Jan; 34:S11-S61. Suppl. 1.

4. Martins RML. A relevância do apoio social na velhice. Millenium - Rev ISPV. 2005;(31):128-34.

5. López DMM, López VMG, Ruiz MEG, López JHP, Escobar AN. Disfunción familiar y control del paciente diabético tipo 2. Rev Med (Mex). 2004;42(4):281-4.

6. Miller CK, Davis MS. The influential role of social support in diabetes management. Topic Clin Nutrit. 2005;20(2):157-65.

7. Toljamo M, Hentinen M. Adherence to self-care and social support. J Clin Nurs. 2001;10:618-27.

8. Lima EDRP, Norman EM, Lima AP. Translation and adaptation of the Social Support Network Inventory in Brazil. J Nurs Scholarsh. 2005;37(3):258-60.

9. Flaherty JA, Gaviria FM, Pathak DS. The measurement of social support: The Social Support Network Inventory. Compr Psychiatry. 1983;24(6):521-9.

10. Torres HC. Avaliação de um programa educativo para controle de diabetes mellitus tipo 2 em Belo Horizonte, MG [Tese de Doutorado]. Rio de Janeiro: Escola Nacional de Saúde Pública Sérgio Arouca, Fundação Oswaldo Cruz; 2004. 126 p.

11. Toobert DJ, Glasgow RE. Assessing diabetes selfmanagement: the summary of Diabetes Self-care Activities Questionnaire. In: Bradley C, editor. Handbook of Psychology and Diabetes. Amsterdam: Harwood Academic Publishers; 1994. p. 351-75.

12. Delgado $A B$, Lima ML. Contributo para a validação concorrente de uma medida de adesão aos tratamentos. Psicol Saúde \& Doenças. 2001;2(2):81-100.

13. Morisky DE, Green LW, Levine DM. Concurrent and predictive validity of a self-reported measure of medication adherence. Med Care. 1986;24(1):67-74.

14. Faria HTG. Fatores associados à adesão do paciente diabético à terapêutica medicamentosa [Dissertação de Mestrado]. Ribeirão Preto: Escola de Enfermagem de Ribeirão Preto da Universidade de São Paulo; 2008. 146 p. 15. Pace $A E$, Ochoa-Vigo $K$, Caliri $M H L$, Fernandes APM. O conhecimento sobre diabetes mellitus no processo de autocuidado. Rev. Latino-Am. Enfermagem. 2006;14(5):728-34.

16. Zou KH, Tuncali K, Silverman SG. Correlation and Simple Linear Regression. Radiology. 2003;227(3):61722.

17. Gomes-Villas Boas LC, Santos CB, Foss-Freitas MC, Pace AE. A relação entre o apoio social e as características sociodemográficas das pessoas com diabetes mellitus. Rev Gaúch Enferm. 2009;30(3):390-6.

18. Mota DDCF, Pimenta CAM. Avaliação e mensuração de variáveis psicossociais: desafio para pesquisa e clínica de enfermagem. Rev Gaúch Enferm. 2007;28(3):30914.

19. Garay-Sevilla ME, Nava LE, Malacara JM, Huerta R, Léon JD, Mena A, et al. Adherence to treatment and social support in patients with non-insulin dependent diabetes mellitus. J Diabetes Complications. 1995;9(2):81-6.

20. Wang CY, Fenske MM. Self-care of adults with noninsulin-dependent-diabetes mellitus: influence of family and friends. Diabetes Educ. 1996;22(5):465-70.

21. Davis MS. Variations in patients' compliance with doctors' advice: an empirical analysis of patterns of communication. Am J Public Health. 1968;58(2):274-88.

22. Johnson SB. Methodological issues in diabetes research. Diabetes Care. 1992; 15(11):1658-67.

23. Wilson W, Ary DV, Biglan A, Glasgow RE, Toobert DJ, Campbell DR. Psychosocial predictors of self-care behaviors (compliance) and glycemic control in noninsulin-dependent diabetes mellitus. Diabetes Care. 1986;9(6):614-22.

24. Westaway MS, Seager J, Rheeder P, Van Zyl D. The effects of social support on health, well-being and management of diabetes mellitus: a black south African perspective. Ethn Health. 2005;10(1):73-89.

25. Duff EM, O'Connor A, McFarlane-Anderson N, Wint YB, Bailey EY, Wright-Pascoe RA. Self-care, compliance and glycaemic control in jamaican adults with diabetes mellitus. West Indian Med J. 2006;55(4):232-6.

26. Grant RW, Devita NG, Singer DE, Meigs JB. Polypharmacy and medication adherence in patients with type 2 diabetes. Diabetes Care. 2003;26(5):1408-12.

Received: Dez. $15^{\text {th }} 2010$ Accepted: June $27^{\text {th }} 2011$ 